\title{
LOS TRASTORNOS DE LA CONDUCTA ALIMENTARIA: ¿MENOS ES MÁS?
}

\author{
Díez Fernández, Teresa*; Yegler Velasco, Carmen*; \\ Casas Martínez, Francisca*; Gómez Carrasco, José Ángel **; \\ Gomez González, Jorge Luis ***
}

* Profesoras Titulares del Dep. de Enfermería; Escuela de Enfermería y Fisioterapia. Universidad de Alcalá. ** Profesor Asociado del Dep. de Especialidades Médicas. Facultad de Medicina. Universidad de Allcalá. **** Profesor Ayudante del Dep. de Enfermería; Escuela de Enfermería y Fisioterapia. Universidad de Alcalá.

e-mail: teresa.diezf@uah.es

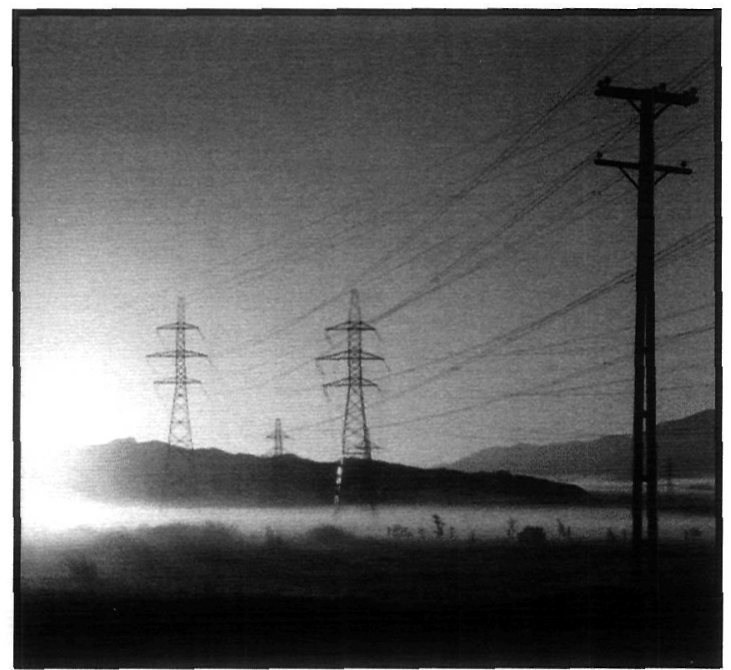

SUMMARY

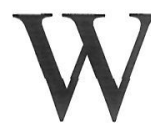
e have wondered if the disorders of the alimentary conduct (DAC) are an exclusive and recent phenomenon of the Western societies, produced or encouraged by the mass media (MM) and, if it is so, who they could have been the changes experienced in the ethical values of our societies that have encouraged the peak of these pathologies along the 20th century. We concluded that conducts similar to what we today identified like DAC (anorexia nervosa and/or bulimia), they have existed from the antiquity. Probably from the incorporation of the Christianity to the history of the Western civilization, previous influence of this of eastern religious values that established a separation body-soul or matter-spirit. In cultures with their views are far apart from the Westerner, the DAC they virtually have not existed and they only appear after the incorporation of the ethical values of the occident developed to the same. The MM influences mightily in the experience of the own image that has the people, particularly the women. The universality of the prototype of high and thin woman, it lead to a distortion of the own corporal image that predisposes to the mental disorder. The change of what it traditionally was considered wealth and social value happened to end of the 19th century and beginnings of the 20th century, next to the incorporation of women into the workforce in the cities, they coincide step to step with what, concerning the aesthetics, it occurred in calling the modern style and that of the new woman; "less is more" it is the leitmotiv. Anorexia nervosa and bulimia are logical consequence of the prevaling norm.

Key words: Disorders of the alimentary conduct. Nervous anorexy. Nervous bulimia. Corporal aesthetics. Means of communication of masses.

\section{RESUMEN}

$\mathrm{N}$ os hemos preguntado si los trastornos de la conducta alimentaria (TCA) son un fenómeno exclusivo de las sociedades occidentales, de reciente aparición, producido o alentado por los medios de comunicación de masas (MM) y, si es así, cuáles han podido ser los cambios experimentados en los valores de nuestras sociedades 
que han alentado el auge de estas patologías a lo largo del siglo XX. Concluimos que conductas semejantes a lo que hoy identificamos como TCA ( $\mathrm{AN}$ y $\mathrm{BN}$ ), han existido desde la antigüedad. Probablemente desde la incorporación del cristianismo a la historia de la civilización occidental, previa impregnación de éste de valores religiosos orientales que establecían una separación cuerpoalma o materia-espíritu. En culturas alejadas de la occidental, los TCA virtualmente no han existido y sólo aparecen tras la incorporación de los valores del occidente desarrollado a la mismas. Los MM influyen poderosamente en la vivencia de la imagen propia que tienen las personas, particularmente las mujeres. La universalización del prototipo de mujer alta y delgada, conduce a una distorsión de la propia imagen corporal que predispone a la sicopatología. El cambio de lo que tradicionalmente se consideró riqueza y valor social acontecido a finales del s. XIX y comienzos del XX, junto a la incorporación de la mujer al mundo del trabajo en las ciudades, coinciden paso a paso con lo que, respecto a la estética, se dio en llamar el estilo moderno y el de la nueva mujer; "menos es más" es el lema. La anorexia y la bulimia son consecuencia lógica de la norma imperante.

Palabras clave: Trastornos de la conducta alimentaria. Anorexia nerviosa. Bulimia. Estética corporal. Medios de comunicación de masas.

\section{INTRODUCCIÓN}

Existe un prejuicio que ha impregnado la opinión pública y la de los propios profesionales de la salud, que tiende a pensar que los trastornos de la conducta alimentaria (TCA), tales como la anorexia y la bulimia nerviosas, son enfermedades "modernas", propias de los países ricos, con elevado nivel de desarrollo y en gran parte causadas por la presión que los medios de comunicación de masas (Mass Media; MM), producen sobre las personas jóvenes, particularmente mujeres, para mantener un determinado estándar físico. Pero ¿es cierto esto?, o, por el contrario, ¿trastornos del tipo de los mencionados han ocurrido en la historia de los hombres en otras épocas?. ¿Es cierto que los MM proponen estándares corporales concretos, y si es así, la presión desarrollada por aquellos verdadera- mente influye en las conductas de las personas?. ¿Qué tipo de valores o qué cambio se ha producido en ellos para explicar la corriente mediática que propone estándares corporales tan diferentes de los tradicionales?. A responder estas preguntas dedicamos las páginas siguientes, tras haber consultado la bibliografía oportuna.

\section{1 ¿De qué hablamos cuando nos referimos a} los trastornos de la conducta alimentaria?.

Los trastornos de la alimentación son entidades potencialmente fatales que los niños mayores y los adolescentes, especialmente mujeres, experimen$\tan$ con creciente frecuencia. La anorexia nerviosa es una conducta caracterizada por el rechazo voluntario de los alimentos por sentirse, verse o considerarse obesa, a pesar de que en muchos casos el peso corporal está muy por debajo del correspondiente para la edad y actividad que desempeña. Los trastornos en relación con las conductas alimentarias (TAC), son principalmente la anorexia nerviosa (AN), la bulimia nerviosa (BN) y el trastorno polifágico (TP). Entre una conducta considerada normal respecto a la alimentación y el extremo de la $\mathrm{AN}$, existe un espectro continuo de conductas, algunas de las cuales, aunque discretamente alejadas de la "normalidad", pueden ser reconocidas como patológicas y llegar a ser el sustrato en el que se podrán desarrollar las situaciones más extremas. Conscientes de esa dificultad a la hora de caracterizar esta variedad de comportamientos que se alejan progresivamente de la normalidad, la Academia Americana de Psiquiatría publicó el Diagnostic and Statistical Manual of Mental Disorders (DSM-IV) en 1994 y la Academia Americana de Pediatría publicó el Diagnostic and Statistical Manual for Primary Care (DSM-PC)en 1996. Ambas elaboraron unos criterios combinados para definir lo que se considerarían trastornos alimentarios del espectro Dieta - Anorexia Nerviosa; Purga/Tratorno Polifágico Bulimia Nerviosa y criterios para definir lo que se consideran Trastornos Alimentarios No Específicos (TCANE). Pronto se vio la necesidad de reconocer que en ambos espectros de alteración existen distintos niveles de patología, de modo tal que hoy se admite el concepto "variante", como el nivel mínimo en que se puede decir que existe ya una alteración de la conducta alimentaria, un nivel 
"problema", cuando el nivel de trastorno es ya más evidente y finalmente la condición de "anorexia o bulimia" (AN o BN), cuando se cumplen los criterios completos.

\section{2 ¿Los trastornos de la conducta alimentaria} (TCA) son de reciente aparición en el siglo XX?

Tres fuentes de conocimiento deberían arrojar luz sobre este interrogante: en primer lugar la historia de la medicina y enfermería que relate algún trastorno que pueda ser semejante, aunque fuera con diferente nombre (o nombres) del que ahora damos a estas anomalías del comportamiento. Con la historia intentaremos responder a ¿cuándo hacen su aparición en la historia del ser humano? Pero no sólo la investigación histórica, sino la epidemiológica podría ofrecer datos sobre cuál es la evolución de estos procesos en las colectividades humanas a lo largo del tiempo. Con la epidemiología responderemos a ¿cómo han evolucionado a lo largo del tiempo? y ¿qué modificaciones han experimentado?. Finalmente, el conocimiento médico y la investigación básica podrían ofrecer hipótesis patogénicas, de modo tal que si reconociesen un origen físico, bioquímico, pensaríamos que más probablemente estos trastornos hubieran existido siempre.

\subsection{La patogenia.}

Tradicionalmente se afirmaba que la anorexia nerviosa y la bulimia no son enfermedades físicas, aunque los efectos y las consecuencias lo sean. Estos trastornos nutricionales se han considerado una enfermedad mental, siendo así porque el cerebro rechaza la imagen real del cuerpo por un ideal físico inalcanzable que les haga ser aceptados y admirados por los que les rodean. Actualmente podemos concluir que la etiología de la $\mathrm{AN}, \mathrm{BN}$ y TP probablemente radica en una combinación de factores biológicos, psicológicos y sociales, que interaccionando contribuyen a la predisposición, el desencadenamiento y la perpetuación de estos trastornos. Los datos que se publican actualmente sugieren una importante predisposición biológica a la AN y BN. De los estudios familiares se puede afirmar que hay un elevado índice de agrupación de casos en familias, de modo que actualmente se considera que la predisposición en madres y her- manas de casos de AN es notable. Actualmente se piensa que el componente heredable de la AN está en torno al $50-90 \%$ y el de la $\mathrm{BN}$ en un $35-50 \%$. Recientes estudios apuntan a un trastorno del metabolismo de la Serotonina (5HT-2-A), que tendría dos peculiaridades: a) dicho trastorno sería más propicio a manifestarse en mujeres, y b) que el trastorno comenzaría a manifestarse únicamente en situación de malnutrición. Es decir la condición genética impondría un umbral, y sólo superado el umbral por una malnutrición, se desencadenaría la AN propiamente dicha. De ser ciertas estas hipótesis habría que reconocer que a lo largo de la historia del hombre la $\mathrm{AN}$, probablemente de origen genético, haya existido siempre. El matiz que introduce el hecho de que para su plena manifestación clínica como entidad reconocible, se necesitaría la malnutrición previa, podría justificar periodos de la historia del hombre con diferente incidencia de los mismos, en función de la disponibilidad y del uso que las personas hayan hecho de los nutrientes.

\subsection{La historia, ¿qué nos dice de la presencia de la AN en épocas pretéritas?}

En sentido estricto probablemente la anorexia nerviosa, tal y como la conocemos actualmente, como un trastorno profundo de la personalidad, de origen no totalmente claro, ha existido en épocas lejanas. Así, de hecho, hubo una ola de anoréxicas a finales del XIX (Freud hablaba de 'la muy conocida anorexia nerviosa'), aunque, por entonces, el modelo de belleza en la mujer exigía carnes opulentas. Tradicionalmente las primeras descripciones son las de Gull (1873) y Lesque (1873). Sin embargo estudios de algunos eruditos de reciente publicación, citados en una excelente revisión del tema de Jules Bemporad, demuestran que el ayuno autoimpuesto ha existido desde siglos, aunque se reconoce que estas acciones voluntarias de autorrechazo variaron a lo largo de los diferentes periodos de la historia, lo cual sugiere que combinaciones de elementos sociales y económicos pueden facilitar o inhibir la expresión de este comportamiento sicopatológico.

Estudios antropológicos demuestran marcadas diferencias en la tasa de anorexia en las diferentes culturas. En lo que a la cultura occidental se refie- 
re podemos asegurar que no hay descripciones de tal condición hasta la era helenística. No hay casos comunicados en la Grecia Clásica, aunque sí existían casos de sobrealimentación voluntaria. De entre las primeras comunicaciones de ayunantes destacan sobre todo las de los eremitas y ascetas, generalmente motivados por ideales religiosos. En la Europa greco-romana, con la llegada del conocimiento de las religiones del este Asiático, se incorpora la dicotomía cuerpo-alma, el cuerpo como algo negativo y el alma como algo positivo, con el consiguiente menosprecio del cuerpo. Esta idea no es sólo incorporada por varones autorrecluidos, sino que incluso algunos movimientos espirituales, como el liderado por San Jerónimo, lograron arrastrar a grupos de mujeres de elevada clase social, en Roma, hacia la vida ascética y el ayuno. Alguna de sus seguidoras llegó a ayunar hasta la muerte, en el año 383, lo que constituirá el primer caso de anorexia con resultado de muerte conocido; caso que obligó a San Jerónimo a huir a Belén para salvar la vida.

Con la caída del imperio romano y la llegada de la Edad Media (los "años oscuros"), disminuyen drásticamente los comportamientos de ayuno autoinducido, a causa de la dureza de la vida diaria, a menudo centrada en la procreación y en la supervivencia a las hambrunas, plagas y guerras en general. Desaparecen ciudades y con ellas la sofisticación y cultura que habían alcanzado las clases sociales elevadas. Durante los siglos del medievo, solo se han relatado 3 casos de anorexia, dos de ellos considerados posesión satánica y curados mediante exorcismo. Un tercero fue el de una joven doncella que, prometida por su padre a un sarraceno, rey de Sicilia, y deseando sólo servir a Cristo, decidió hacerse tan poco atractiva como para que su pretendiente desistiera del empeño. Su padre tuvo que crucificarla por ello, lo que la convirtió en santa.

En el Renacimiento Europeo reaparece numerosa casuística de conductas de autoayuno, particularmente en las ciudades, donde de nuevo emerge la cultura y la sofisticación. Bell, en su libro Holy Anorexia ("Anorexia Santa"), recopila 261 casos de inanición voluntaria en mujeres por razones religiosas, entre 1206 y 1934; de ellas 181 vivieron entre 1200 y 1600 . Algunas fueron santificadas, como santa Catalina de Siena, quien con 26 años se encerró en su habitación, con la idea de dedicar su vida a Dios, no comiendo y consiguiendo ingresar al final en la orden dominicana pero con la mitad de su peso. El prestigio de Catalina de Siena se extendió rápidamente y tras su muerte, a los 28 años, contaba con muchas seguidoras religiosas. El ayuno era un medio para que el espíritu triunfara sobre la carne. Estar sin comer era considerado como un signo de santidad. A esta anorexia sufrida por el seguimiento a Dios se llamó "Anorexia santa".

Desde el renacimiento hasta la actualidad, han persistido casos esporádicos de este tipo de conductas, pero con la llegada de la reforma los valores europeos se reestructuran y disminuyen de forma drástica el número de los mismos. Son de destacar los cambios en la actitud de la Iglesia, que impone varones sacerdotes, como intermediarios entre los hombres y Dios, y cambios en el papel social de las mujeres, impuestos por el puritanismo victoriano, de nuevo valoradas más por sus valores biológicos, que por sus cualidades estéticas. En esta época son pocos los casos de auto-inanición, pero se citan algunos de "doncellas milagrosas", chicas de "cualidad cenicienta", habitualmente procedentes de familias pobres y en áreas rurales, que argumentaban ser capaces de sobrevivir sin nutrientes (existencia etérea). Estas jóvenes eran visitadas como un raro fenómeno, por gente importante, ofreciendo por ello un pago a sus familias. Muchas argumentaban una motivación religiosa para su ayuno. Algunas alcanzaron notoriedad incluso internacional, pero algunas murieron de inanición.

El "goteo" de casos de dietas de hambre autoimpuestas llega hasta el siglo XIX, en que el prestigioso médico de la reina Victoria de Inglaterra, Sir William Gull, describe el primer caso de la historia de la medicina descrito como tal anorexia nerviosa. En esos tiempos de "revolución industrial", una emergente y lucrada clase media florece en las ciudades y tiene aspiraciones culturales y estéticas. Hasta finales del XIX, una mujer corpulenta y no alta era símbolo de la prosperidad de una familia, pero a partir de la revolución industrial ya no se vincula a la mujer con la fuerza del trabajo y emerge la figura frágil y estilizada para 
demostrar que no se necesita el trabajo físico para el éxito económico. Desde finales del XIX hasta nuestros días la historia de la anorexia es bien conocida: destacar que los casos descienden notablemente en las dos Guerras Mundiales, pero salvo en esos dos periodos, el incremento de las dietas de ayuno autoimpuestas no ha cesado.

España no ha sido ajena al devenir histórico de la AN y los TCA en general. En su libro "La vida cotidiana de los españoles en el siglo XX", Amando de Miguel nos recuerda que antes de la Guerra Civil Española ya Don Gregorio Marañón registraba la "moda de la extrema delgadez": "Nunca se ha extendido a mayor número de seres humanos; ni nunca se ha llevado a tales extremos, casi esqueléticos, el prototipo delgado de la figura humana". Por aquél tiempo Rafael Penagos en "Blanco y Negro" dibujaba figuras femeninas delgadas y estilizadas hasta la caricatura. A pesar de todo, en aquellos tiempos, lo general en buena parte de la sociedad española, era la desnutrición. Para la mentalidad tradicional ser gordo era signo de buena salud y buen carácter. Para el mismo Marañón, "los gordos se distinguen de los flacos por caracteres esenciales inconfundibles"; en la cultura tradicional todo el mundo acepta que el sentido común y la bonhomía de Sancho Panza tienen que ver con su grosor. Lo que Marañón denominó moda en los años 30, se ha generalizado algunas generaciones más tarde, cuando en España se ha superado el hambre histórica.

Podemos decir que desde los años 30 y las referencias de D. Gregorio Marañón, en España ha ido calando la doctrina del adelgazamiento; el consejo entonces era para una minoría que podía permitirse el lujo de comer menos, pero hoy la prescripción se ha popularizado.

Para concluir, la historia demuestra que los casos de mujeres con dietas de hambre autoimpuestas no son un fenómeno reciente, ni siquiera del siglo XX. Desconocidos en Occidente hasta que aparece el Gnosticismo, el cual introduce la dicotomía cuerpo=mal $/$ alma=bien. A partir de los primeros siglos de nuestra era cristiana no han cesado de aparecer casos. Lo que ha cambiado en la modernidad es la motivación: en otros tiempos la negación del cuerpo (incluso la sexualidad) para un mayor acercamiento al espíritu, actualmente el miedo a la gordura "per se". La segunda enseñanza de la historia de las conductas anoréxicas es que cuando los alimentos escasean, el número de casos disminuyen hasta prácticamente desaparecer (ausencia de casos en las guerras). La tercera lección que nos enseña es que cuando a las mujeres se las aprecia por sus funciones biológicas y no por valores estéticos, culturales o espirituales, aún en sociedades opulentas, la anorexia no existe, como se puede comprobar en países árabes ricos.

\section{3 ¿La epidemiología que nos aporta?.}

Estudios epidemiológicos que han investigado los TAC a través de las décadas más recientes del s. XX, concluyen que en los últimos 20 años, éstos se han multiplicado por diez. En la cuantía en que actualmente afecta a nuestras sociedades desarrolladas, es indudablemente un fenómeno reciente. Algunos han llegado incluso a hablar de "epidemia" de reciente aparición en nuestras sociedades. Los principales estudios epidemiológicos de los TCA realizados en España, obtienen datos similares entre sí, y semejantes a los citados por la bibliografía internacional (American Psychiatric Association en el DSM-IV). Algunos de estos estudios se exponen en la tabla (I):

La mayoría de los estudios, aún con sus limitaciones, se basan en cuestionarios autorespondidos por las mujeres, por lo que es preciso asumir una tendencia a minusvalorar o a no reconocer la importancia del problema por parte de la propia persona que responde. Es de esperar que los datos obtenidos tengan cierto sesgo a disminuir la magnitud del problema. A pesar de que la creencia que se transmite es de un elevado incremento de los TCA en las sociedades modernas, hay autores que defienden la falta de constatación de este incremento, dado que:

- Es evidente la ausencia de estudios epidemiológicos metodológicamente correctos realizados en épocas suficientemente remotas, como para establecer comparaciones con estudios más recientes, de los que sí hay abundancia.

- Podría ocurrir que el incremento de la prevalencia se relacionase más con el reconocimiento más frecuente del trastorno.

- Podría ocurrir también que el elevado número de hospitalizaciones que se argumenta, tuviese 
una relación grande con el elevado número de reingresos, que sufren las pacientes más graves.

- No se puede descartar una sobre valoración por parte de los mass media.

- Es innegable el notable incremento de profesionales y expertos dedicados a los TCA, lo que también puede contribuir a magnificar la cuantía de los TCA.

Incluso teniendo en cuenta estos interrogantes, parece que revisiones exhaustivas de los estudios disponibles concluyen que, como promedio, la incidencia de anorexia nerviosa ha pasado de 0,37 por 100.000 habitantes y año, en la década de los 60 , a 0,64 en la de los 70 y hasta un 6,3 en la de los 80. Son dignos de mención los estudios de Lucas y cols en Rocherter (Minesota) y de Pagsberg y cols en Bornholm (Dinamarca); ambos, trabajos retrospectivos, pero de gran envergadura, abarcando poblaciones completas y periodos largos. Lucas y cols estudian una población de 13559 historias clínicas de mujeres y observa una incidencia de AN en el grupo de 10 a 19 años del 16,6 por 100.000 personas/año entre 1935-1939; de 7 por 100.000 personas/año entre $1950-54$ y de 26,3 por 100.000 personas/año entre 1980-84; la incidencia en mujeres mayores de 20 años permaneció constante en el periodo observado. Pagsberg y cols en su estudio basado en una población de 47000 personas, entre 1970 y 1989, hallan que la incidencia de AN permanece relativamente estable en el periodo del estudio, pero demuestran un significativo incremento en los 5 años últimos, así entre 1970-74 la incidencia de AN fue de 1,6 por 100.000 , mientras que entre 1985-89 la incidencia fue del 6,8 por 100.000; en el grupo de mujeres de 10 a 24 años (grupo de máximo riesgo) fue de 136 por 100.000 en el año 1989.

El incremento de los años 80 ha sido unánime en Japón, América del Norte (USA y Canadá) y Unión Europea. Todo apunta a que el incremento en estas áreas geográficas ha ido paralelo a la difusión de los valores occidentales que acompañan al desarrollo socioeconómico y más concretamente a la difusión del modelo estético corporal femenino delgado cuya vigencia se inicia en Occidente tras la $1^{\text {a }}$ Guerra Mundial, y que se generaliza tras la $2^{\mathrm{a}}$ Guerra Mundial.
3 ¿Cuál es el papel que juegan los medios de comunicación de masas en el estado actual de los T.C.A en nuestras sociedades occidentales desarrolladas?.

Se tiende a creer que las presiones socioculturales influyen notablemente en la prevalencia de la insatisfacción corporal en la actual sociedad occidental. A pesar de lo que parece una voz unánime en medios científicos y no científicos, existen voces discordantes que afirman que: "la moda, la talla, los desfiles, las fotos de mujeres esqueléticas que se ven en revistas y periódicos y la publicidad no están, lo dicen los mejores estudios, en los primeros puestos de una lista (de factores favorecedores) aún mal delimitada", según afirma José Luis de la Serna en el diario El Mundo. Y continúa: "La anorexia y la bulimia son enfermedades muy complejas. Sin duda alguna, existen condicionantes biológicos aún por descubrir con precisión, que influyen de una manera clara en el riesgo de sufrir estas enfermedades".

Los mensajes respecto del ideal femenino son transmitidos desde una gran variedad de fuentes: la familia, los y las compañeras y los medios de comunicación. La naturaleza ubicua de los MM les confiere un poder especial en la capacidad de influir sobre las actitudes sociales. El cambio en la representación de la figura femenina en los $\mathrm{MM}$ es algo relativamente reciente. En la sociedad occidental el ideal de mujer dominante es delgada, alta y de piernas largas. La relación entre la imagen corporal femenina y los MM ha sido objeto de una excelente revisión realizada por Sarah Durkin, de la que exponemos las ideas de los párrafos que siguen. En primer lugar que la constatación del "desplazamiento" de la figura femenina en los MM hacia la delgadez, ha sido documentado por vez primera por Garner y cols en 1980, quienes demostraron un significativo descenso de las medidas y pesos en los posters de Playboy y en las elecciones para Miss América, entre los años 1959 y 1978. Paralelamente a este cambio se produjo un incremento significativo de artículos referentes a dietas en semanarios dirigidos a mujeres en el mismo periodo de tiempo. Un análisis más reciente centrado en 21 semanarios de los considerados femeninos, a lo largo de 1996, encontró que el 78\% de los temas tratados se referían a la apariencia cor- 
poral. Otros autores han comprobado que el $94 \%$ de los tipos femeninos mostrados en televisión son mujeres jóvenes con un peso claramente inferior al de la media de la población general. Estos hechos contrastan con la mujer "real" que ha demostrado incrementar su peso en las sociedades desarrolladas. Esto produce una gran distorsión y falseamiento de la representación del ideal de mujer, siendo el presentado por los MM inalcanzable para la mayoría de ellas, sin un cuidado extremo de la dieta o de la actividad física.

¿Qué impacto sobre la satisfacción con su propio cuerpo tiene en las mujeres la exposición este tipo de idealización femenina representado de forma dominante en los MM? Durkin cita en su revisión una gran cantidad de estudios, la mayoría realizados en los recientes años 90 , que ponen en evidencia algunas ideas: $1^{\text {a }}$ ) Niñas y adolescentes pasan muchas horas viendo televisión, de hecho es la actividad a la que dedican más tiempo, después de dormir. Igualmente la lectura de magazines de moda es una actividad de ocio también importante entre las adolescentes. $2^{\mathrm{a}}$ ) Las mujeres frecuentemente se comparan a sí mismas con las imágenes idealizadas de los MM. $3^{\text {a }}$ ) Los estudios experimentales diseñados para buscar el grado de insatisfacción que produce en las mujeres la contemplación de la figura femenina ideal de los MM muestran resultados contradictorios. Cuando se han buscado las razones para la discordancia de resultados, se ha comprobado que es posible diferenciar subgrupos de mujeres más vulnerables a la influencia de los MM. Así las que demuestran alguna alteración de la conducta alimentaria (las denominadas "variantes"), las adolescentes, las mujeres con sobrepeso, las mujeres que aceptan un papel más tradicional y las que tienen menor autoestima, parecen claramente más influenciables. El nivel previo de satisfacción o insatisfacción con su propia imagen corporal es el principal predictor del estrés que añade la contemplación de la figura femenina idealizada en los MM y esto es válido tanto para grupos de mujeres feministas, como las que no participan de esta ideología.

Es importante destacar un estudio, realizado en 548 escolares americanas de 5 a 12 años de edad diseñado para valorar la influencia de los MM sobre la preocupación de las chicas respecto del propio peso, control del mismo, autopercepción y comportamientos alimentarios. Este trabajo es el primero que demuestra el impacto de los medios impresos sobre los items citados y demuestra que la mayoría de las preadolescentes y adolescentes, se encuentran insatisfechas con su propio peso y forma y el descontento está fuertemente relacionado con la frecuencia de lecturas de magazines de moda. Su lectura se asoció positivamente con la prevalencia de realización de dietas restrictivas encaminadas a la pérdida de peso y realización de ejercicio para perder peso o modificar la forma corporal. Algunos otros estudios se citan en la tabla II, en la que se expone la conclusión principal de los trabajos.

En España un estudio realizado por el Servicio de Psquiatría y Psicología Médica del Hospital Clínico de Barcelona, ha desvelado el papel que los factores socioculturales juegan en dichos trastornos. Y ha llegado a la conclusión de que la publicidad de productos adelgazantes, las lecturas sobre el cuerpo y el peso, el cuerpo de las modelos y mujeres populares, los comportamientos de las amigas y las actitudes familiares son los principales agentes de transmisión de la "cultura de la delgadez". Los cuerpos de las modelos y las gimnastas son los más envidiados. Este tipo de modelos supone un riesgo potencial añadido. Uno de los autores, el doctor Josep Toro, jefe del Servicio de Psquiatría Infantil y Juvenil del Hospital Clínico y Provincial de Barcelona explica: "Desde hace tiempo se sabe que las bailarinas y las modelos tienen actitudes y patrones de comportamiento muy cercanos a la patología. Estudios recientes han confirmado la existencia de trastornos del comportamiento alimentario en bailarinas, gimnastas, ...”. Por su importancia y por ser un estudio llevado a cabo en nuestro país, exponemos algunas de sus conclusiones más destacadas: Se trata de un cuestionario dirigido a 675 jóvenes y adolescentes del sexo femenino de Barcelona. 430 de ellas pertenecían a la clase media-alta y cursaban séptimo de E.G.B. y C.O.U. 245 chicas restantes eran universitarias. La mitad de ellas había decidido perder peso y la mayoría estaba preocupada por él. Más de la mitad de esta población se interesaba por publicaciones relativas al peso, al adelgazamiento y al control de la obesidad. Los anuncios de pro- 
ductos adelgazantes interesaban a casi la mitad de la población estudiada. Se destaca la importancia de la publicidad en las farmacias que, aunque menos espectacular, tiende a presentar los productos con un cierto halo científico. En este sentido, la investigación desvela que entre el 15 y el $20 \%$ del grupo universitario consultado confesó interesarse por los productos laxantes. Los anuncios destinados específicamente a la pérdida de peso impactaban especialmente en la población femenina de entre 14 y 24 años de clase social media y mediaalta que vivían en poblaciones de más de 50.000 habitantes. Dos tercios de la muestra admite su gusto por los cuerpos femeninos extremadamente delgados. El 30\% de la muestra siempre envidia a las modelos de alta costura o a las que anuncian las prendas de vestir. "Con estas actitudes, dice el análisis, no debe sorprendernos que prácticamente el $80 \%$ juzgue, más o menos sistemáticamente, a las actrices según su gordura o delgadez". Sólo un $13 \%$ de la muestra manifiesta que no tienen amigas que estén o hayan estado a dieta para adelgazar. Un tercio afirma que tienen más de 3 amigas que siguen una dieta.

En conclusión, la representación del cuerpo femenino en los MM es irrealmente delgada, y la exposición frecuente a este tipo de representación tiene efectos negativos cuando se comparan consigo mismas. Esta repercusión no es idéntica en todo tipo de mujeres, sino que pueden diferenciarse grupos vulnerables. Aunque los factores socioculturales no son la base etiológica de los TCA, sí es cierto que son elementos que configuran esta patología psiquiátrica, influyendo en los grupos de población más vulnerable.

La Comisión de Cultura y Educación del Senado Español tras oír las conclusiones de un grupo de 88 expertos de diferentes disciplinas del Comité de Trastornos de la Alimentación del senado, acuerdan considerar que: la familia, los medios y la industria de la moda son responsables de promover una serie de valores a favor de la cultura del cuerpo y delgadez extrema, frente a los más importantes valores de la cultura, y los hábitos saludables. Concluyen que la anorexia nerviosa y la bulimia son trastornos multicausales con una serie de condicionantes culturales que actúan como desencadenantes y marcan su perpetuación.

\section{4 ¿Son los T.C.A propios de la cultura occiden- tal?}

Una gran parte de expertos coincide en que estos trastornos son propios de sociedades desarrolladas, hasta ahora no parecen afectar a poblaciones más pobres y aisladas de los patrones de vida occidentales. Pero es preciso destacar una escasez de estudios prospectivos de seguimiento de comunidades predesarrolladas y su evolución tras la incorporación al mundo desarrollado. Uno de los más destacados y recientes es el llevado a cabo por Anne Becker, de la Harvard Medical School. El estudio, llevado a cabo en las Fiji, es de diseño longitudinal, e investiga los cambios en las conductas alimentarias en las adolescentes de dicho archipiélago, entre los años 1995 y 1998, tras la introducción de la televisión. La súbita inmersión en los valores de la cultura occidental, a través de la televisión, hizo que las adolescentes de las islas Fiji, renegaran de la tradicional imagen corporal. Según Becker, en una encuesta realizada en 1998, exactamente 38 meses después de que comenzara a transmitir su señal el primer y único canal de televisión en Fiyi, un 74\% de las niñas del país dijeron sentirse "muy corpulentas o gordas". La programación del canal consiste en series británicas, australianas y estadounidenses, como Seinfeld, ER, Melrose Place y Beverly Hills, entre otras. El resultado fue un abrupto incremento de trastornos de la alimentación, tales como los vómitos autoinducidos, así en 1998 el 15\% de las adolescentes de 17 años reconocían tal práctica, para controlar su peso, tan solo 38 meses después de la introducción de la TV. En 1995, inmediatamente después de la introducción de la TV, tan sólo reconocieron dicha práctica el $3 \%$.

La imagen corporal era "dosis dependiente" de la TV, así las que veían TV al menos 3 noches/semana, tenían 50\% más de probabilidad de verse gordas y un $30 \%$ de hacer dieta, a pesar de que las más contemplativas de la TV no eran las más gordas. Un $68 \%$ de adolescentes escolares de las Fiji en 1998, reconocían haber hecho algún tipo de dieta en último mes, proporción comparable, o incluso superior a la de las adolescentes americanas.

Tradicionalmente, la gente de Fiji ha preferido y valorado, tanto entre los hombres como en las 
mujeres, lo que Becker describe como "un cuerpo robusto y musculoso". La frase "aumentaste de peso" siempre fue considerada un piropo entre la gente de estas islas, mientras que una pérdida de peso era vista como un problema de salud preocupante. En Fiji, los invitados a cenar deben comer lo más que puedan, de acuerdo con las reglas de buenos modales. La imagen corporal tradicionalmente valorada en las Fiji era de una mujer robusta, reflejo de la importancia de la alimentación generosa y del buen apetito. La posición social tiene que ver con el modo de comer. "En cualquier comida, especialmente cuando has sido invitado, debes comer cuanto puedas, a menudo más allá de la saciedad". Para los oriundos de este país, "tener las piernas flacas" era un insulto. La sociedad de Fiji ha sido tradicionalmente hipervigilante y recelosa con las personas de poco comer, identificando una enfermedad específicamente cultural llamada "goin thin" (hacia la delgadez), significando pérdida de peso notable.

Solo en los años muy recientes, como reflejo de la usurpación de los valores e ideales de belleza occidentales, las Fijianas han comenzado a preocuparse por el exceso de peso. Fiji se ha desarrollado desde un aislamiento hacia una integración en la cultura de economía globalizada. Ha pasado de una sociedad agraria a una sociedad de la información. Los valores tradicionales han sido cuestionados por las generaciones jóvenes. Las adolescentes de Fiji a menudo tienen dificultades para aceptar que la TV no refleja fielmente la vida americana. "Nosotros podemos ver a las adolescentes en la TV. Ellas tienen la misma edad, ellas trabajan, son delgadas y muy altas y son lindas y guapas.... Nosotras queremos que nuestros cuerpos se parezcan, ... por tanto vamos a intentar perder mucho peso". Según la científica de Harvard, "en el siglo $\mathrm{XX}$, la televisión es otro patógeno que exporta las imágenes y los valores de las culturas occidentales".

\section{5 ¿Cómo se ha llegado a la expansión de los TCA en el mundo occidental en el final del siglo XX?}

En las reflexiones de este apartado seguimos básicamente las líneas expuestas por Stuart Ewen, profesor del Hunter College, en su libro "Todas las
Imágenes del Consumismo". La economía tradicional a lo largo de la historia de la humanidad se ha basado en los bienes materiales y "terrenales", entendidos éstos como las posesiones de objetos, tierras y espacios ("bienes duros"). Dentro de los límites de la sociedad agraria autosuficiente y localizada, no se concebía una riqueza que no ocupara un espacio. Aunque la historia del dinero es antigua, no ha sido hasta la mitad del siglo XIX cuando la preeminencia de estos bienes duros cede paso al valor de lo abstracto, lo inmaterial y efímero. A finales del XIX el mundo moderno llega a otorgar valor a nuevos productos y servicios: comienza a surgir la idea de que el dinero grande se hace en los mercados especulativos y evanescentes, la bolsa, los bonos, el manejo de la información. Son los "nuevos valores". Así se llega a la situación actual en la que parecen tener poca importancia los requisitos materiales, en un mundo de ganancias especulativas. Gana terreno a velocidad de vértigo la concepción, cada vez más abstracta, del valor económico. Hoy el comercio trepidante en los mercados financieros tiene muy poco que ver con la producción de bienes y servicios reales. "El sistema producía antes mercancías, pero ahora sobre todo sueños", dice Vicente Verdú.

El New York Times en un informe de 1987 hace el retrato robot del nuevo tipo de trabajador predominante en el mundo de hoy: "el nuevo trabajador no es un obrero de la industria del automóvil o un minero del carbón o de la siderurgia. Es más probable que él sea un ejecutivo, un trabajador de oficina o casa financiera sentado frente a un terminal de ordenador, o un consultor, un dispensador de comida rápida que calienta hamburguesas deshidratadas por congelación, o un repartidor de pizza".

La economía real de bienes y servicios y la economía simbólica del dinero, el crédito y el capital ya no se hallan vinculadas estrechamente, y cada vez se separan más. La supervivencia continúa adherida a la disponibilidad de bienes materiales, pero la riqueza económica deriva más que nunca, de la circulación de representaciones de lo que realmente vale ("el valor"). En los EEUU desde los años 20 el crédito se fue convirtiendo progresivamente en el principal modo de existencia cotidiana. Esto, en nuestro país, podría no ser real hasta bien 
entrados los años 60 , pero el resultado final ha sido similar: el dinero en sí mismo ha sido devaluado como demasiado pesado. Hoy el empleo de dinero contante y sonante se ha convertido en indicador de pobreza o de ilegitimidad (vendedores ambulantes, traficantes, etc). Hoy los signos de solvencia se han vuelto cada vez más invisibles. El rico del s.XIX y a comienzos del XX podría describirse como acumulador de sacos de dinero y ostentando gruesos fajos de billetes; actualmente la carga de la riqueza se ha aligerado considerablemente. La tarjeta de crédito es abstracción de la abstracción: la metaabstracción, podríamos llamarla. Las posesiones tangibles del terrateniente han cedido paso a las pertenencias quiméricas del especulador: lo de menos se ha tornado en lo de más. Los ricos y advenedizos de hoy se rodean de los logros de la abstracción.

La estética y el estilo no podían permanecer al margen del cambio tan importante, único en la historia de la humanidad. En el estilo moderno se imprime la apreciación del valor transitorio e incorpóreo, como veremos a continuación: MENOS ES MÁS ha sido y es el lema del estilo de la modernidad. Es en los s. XIX y XX, cuando emergen en la historia de la humanidad la economía del dinero, el crédito y la especulación, cuando comenzó a buscarse deliberadamente lo que podría denominarse una "estética de abstracción ingrávida". El arquitecto Peter Berhens llega a decir: "La arquitectura se esfuerza hacia el infinito; pero más que cualquier otro arte permanece ligada a los materiales tangibles. Por esta razón no puede trasladarse a sí misma a las esferas de un mundo trascendental en el cual se transforme en una idea. Permanece atada a la tierra", y más tarde él reflexionaba así: "el éxito del diseño industrial estriba en establecer la cantidad mínima de material para una determinada construcción y la belleza del hierro y el acero consiste parcialmente en su rigidez sin volumen". La nueva sociedad del dinero-crédito-especulación imprime una nueva huella en la mente de los arquitectos, diseñadores y vendedores de imágenes cuyo trabajo llegaría a abarcar gran parte de lo que entendemos como estilo moderno. Walter Gropius alababa las cualidades del vidrio como material de construcción, y la característica que lo hace más atractivo es "su bri- llante insustancialidad y con él puede lograrse una preponderancia de los vacíos sobre los sólidos".

La arquitectura puede ser vista como una retórica visual que refleja los cambios en el significado de lo que se entiende por riqueza y de lo que tiene valor. La construcción de los rascacielos materializa la esencia de la forma que busca el máximo beneficio. Así sin aumentar su área de terreno, el valor del bien raíz escala niveles tan altos como lo permitan la codicia y la ingeniería.

Ya en la década de los 20 la teoría cada vez más abstracta de lo valorado, va más allá de los límites de la arquitectura y los nuevos principios estéticos dejan huella en el estilo. "Menos es más" se repite una y otra vez en todos los campos de la estética. La moda femenina fue uno de los campos donde prende rápido este concepto. El cambio en el papel social de la mujer, con la incorporación de ésta al mundo laboral y el fenómeno de la urbanización imparable del mundo, alejan a las mujeres del convencionalismo victoriano. La definición del valor en el universo femenino ha experimentado una transformación radical en el s. XX y la reforma de la ropa fue un elemento esencial en la liberación femenina, para responder a las aspiraciones sociales de las mujeres. Los vestidos se hacen más cortos y se impone la línea recta en el vestir. "La ropa sigue el espíritu del boceto", se ha llegado a decir. Mientras las tradicionales modas femeninas dependían de un cuerpo sólido, las nuevas tendencias desplazan el idioma terrestre de la expansión horizontal, hacia la liberada verticalidad. La joven emancipada de los 20 era ágil, casi ingrávida.

En el curso del s. XX, la estética del valor abstracto ha dejado huella en la arquitectura, el diseño de productos, la moda, el empaque, incluso el lenguaje ha sido afectado por una cierta escasez. Sin embargo, por encima de todo eso, su efecto sobre los ideales del cuerpo humano es particularmente notable. En ninguna parte puede demostrarse con mayor profundidad el estilo y la transformación estética del valor como en la evolución de los ideales corporales desde el comienzo del siglo XX. Siguiendo a Stuart Ewen podemos afirmar que los estadounidenses de finales del XIX, aún valoraban la gordura como signo de vida de auto-satisfacción y abundancia; aunque la revolución del dinero y del valor de lo abstracto ya estaba en marcha, las 
clases medias aún no estaban preparadas para que los nuevos valores se reflejaran en la concepción moderna de los cuerpos. Para la gente pobre, por supuesto que un cuerpo bien alimentado tenía un atractivo evidente. En los primeros años del s. XX el peso no había llegado a ser un problema que resolver. Es a finales de la $1^{\text {a }}$ Guerra Mundial cuando el cuerpo femenino se separa de las nociones de fertilidad y abundancia material y llega la incorporación de las mujeres al mundo del trabajo en la sociedad industrial urbana. Cobra importancia la esfera social y la liberación de la sexualidad reproductora. En este proceso el valor de la mujer cambió y surge un nuevo ideal de cuerpo femenino, impregnado de las características volátiles del valor mercantil abstracto. De acuerdo al sistema dominante de la rentabilidad que llega a sustentarse en una base de mero aire, el cuerpo femenino siguió el ejemplo, imitando la inmaterialidad de un dinero fluctuante. Ya a mediados del s. XX se ha consolidado el modelo de "la nueva mujer", como así era denominada por numerosos medios de comunicación: "delgada, alta, vigorosa, parecida a una pantera". El contorno "recto de arriba abajo" que estaba naciendo superó las formas voluptuosas; la nueva cultura, especialmente en los medios de comunicación de masas, vende las virtudes de la esbeltez. Las maniquíes estandarizadas se convierten en el ingrediente básico de la publicidad para vender cualquier cosa, desde automóviles hasta tabaco, con las ideas de que menos es más. Los periodos de guerras y depresión económica hacen alguna concesión a la idea tradicional del físico abundante, pero la trayectoria general del s. XX, desde la década de los 20 ha sido de tendencia continua hacia una sustancia siempre en disminución. Un tipo corporal esbelto para la "mujer moderna" debe interpretarse a la luz de su gradual emancipación del enclaustramiento tradicional de un espíritu y un hogar patriarcales.

Pero... la insaciable pasión por la silueta delgada, resulta en el fondo, antagónica con la necesidad biológica del cuerpo de ser alimentado; el nuevo espíritu, el nuevo valor se contrapone a la necesidad física, de modo tal que la búsqueda de la inmaterialidad puede producir enfermedad. Stuart Ewen concluye en su libro que "la anorexia y la bulimia no son anomalías inesperadas, sino exten- siones lógicas de la norma imperante. Es el núcleo sociosomático del problema, el ideal externo, social, de la delgadez aparece como consecuencia de la modernidad. Habla de una vida que reclama vivir más allá de las consecuencias de la naturaleza. Refleja la lógica pura del valor abstracto -la economía del puro aire- transportada e implantada dentro del reino interior del sujeto humano. Ajustándose a los ideales que han seguido la arquitectura, el diseño y la moda, el cuerpo ideal no existe materialmente, ha sido reducido a una representación abstracta de la persona: una línea, un contorno, una actitud, desollados de sus imperativos biológicos. Sin importar la forma que tome el cuerpo, cualquier carne que permanezca es demasiada".

Esta corrupción fatídica debe ser corregida y Kent Bloomer y Charles Moore, críticos de arquitectura, en su libro "Body, Memory and Architecture", dicen: ".... Una de las consecuencias más peligrosas de suprimir experiencias y temas corporales en la vida adulta puede ser una capacidad disminuida para recordar quién o qué somos. La expansión de nuestra identidad actual requiere un mayor reconocimiento de nuestro sentido de espacio interior, al igual que el del espacio que rodea a nuestros cuerpos. Si continuamos centrándonos en las experiencias externas y novedosas y en las visiones y sonidos que nos dirige el medio ambiente, con exclusión de la renovación y expansión de nuestras experiencias hápticas (considerando éstas como táctiles, incluyendo no solo las manos sino el cuerpo entero como elemento táctil) primordiales, nos arriesgamos a disminuir el acceso a una riqueza de detalle sensual desarrollando dentro de nosotros mismos nuestros sentimientos de ritmo, de los bordes duros y suaves, de los elementos enormes y pequeños, de aberturas y cierres, y una miríada de señales y direcciones, las cuales, si se toman juntas, forman el núcleo de nuestra identidad humana.

\section{CONCLUSIÓN}

I. Los T.C.A no son un fenómeno nuevo en la historia de la humanidad, ya que conductas semejantes a lo que hoy identificamos como tales trastornos (AN y BN), han existido desde antiguo. Muy probablemente desde la incorporación del 
cristianismo a la historia de la civilización occidental, previa impregnación de éste de valores religiosos orientales que establecían una separación cuerpo-alma o materia-espíritu.

II. Queda claro que hay un cambio radical en las motivaciones de las conductas alimentarias anormales: generalmente impregnadas de religiosidad antes del s. XX y meramente estéticas en éste.

III. El incremento de la prevalencia de los TCA en la segunda mitad del s. XX en el mundo desarrollado ha sido espectacular, sin parangón en los anteriores.

IV. Parece razonable afirmar que en culturas ajenas a los valores de nuestra cultura occidental, los TCA virtualmente no han existido y sólo tras la incorporación de los valores del occidente desarrollado, aparecen en las sociedades.

V. Los medios de comunicación influyen pode- rosamente en la vivencia de la imagen propia que tienen las personas y muy particularmente las mujeres. La universalización del prototipo de mujer alta y delgada, conduce a una distorsión de la propia imagen corporal, que predispone a la sicopatología.

VI. Se puede afirmar que el cambio de consideración de valor económico y riqueza de finales del s. XIX y comienzos del XX, que introduce como modelos la especulación, más que la acumulación de bienes, junto con la incorporación de la mujer al mundo del trabajo en las ciudades, coinciden paso a paso con lo que todas las manifestaciones estéticas, comienzan a considerar como el estilo moderno y por supuesto también el de la nueva mujer en el siglo XX, especialmente a partir de los años 20 y 30: "menos es más" es el lema.

\section{TABLA I.}

Prevalencia de los TCA en población femenina, adolescente en algunos estudios.

\begin{tabular}{|c|c|c|c|c|c|c|}
\hline AUTORES & $\begin{array}{l}\text { Lugar- } \\
\text { Año }\end{array}$ & Sexo / Edad & AN (\%) & $\mathrm{BN}(\%)$ & $\begin{array}{c}\text { TCA No } \\
\text { especific } \\
0\end{array}$ & $\begin{array}{l}\text { TCA } \\
\text { totales }\end{array}$ \\
\hline Morandé \& Cols ${ }^{35}$ & $\begin{array}{l}\text { Madrid } \\
1997\end{array}$ & $\begin{array}{l}\text { Mujeres } \\
15 \text { años }\end{array}$ & 0,69 & 1,24 & 2,76 & \\
\hline $\begin{array}{l}\text { Pérez-Gaspar \& } \\
\text { cols }^{36}\end{array}$ & $\begin{array}{l}\text { Navarra } \\
2000\end{array}$ & $\begin{array}{l}\text { Mujeres } \\
12-21 \text { años }\end{array}$ & 0,3 & 0,8 & 3,1 & 4,1 \\
\hline Ruiz PM ${ }^{17}$ & $\begin{array}{l}\text { Zaragoz } \\
\text { a } 2001\end{array}$ & $\begin{array}{l}\text { Mujeres } \\
12-18 \text { años }\end{array}$ & 0,14 & 0,55 & 3,83 & 4,52 \\
\hline $\begin{array}{l}\text { American Psychiatric } \\
\text { Association (DSM-IV) }\end{array}$ & $\begin{array}{l}\text { USA } \\
1994\end{array}$ & & $0,5-1$ & $1-3$ & & \\
\hline
\end{tabular}




\section{Tabla II}

\section{T.C.A Y MEDIOS DE COMUNICACIÓN. ALGUNOS ESTUDIOS CONCLUYEN QUE:}

\section{Estudio. Conclusión principal}

Verri $A^{37}$ y cols. Las pacientes con TCA pasan más horas viendo TV y sus

1997.

compras están más influidas por los anuncios.

Pinhas $L^{38} y$ cols

En adolescentes universitarias, el pase de fotografias de

1999.

modelos, produce humor depresivo e irritabilidad, respecto a

un grupo control al que no se le mostraban figuras humanas.

Field $\mathrm{AE}^{39}$ y cols

De entre 548 mujeres preadolescentes, $69 \%$ reconocen que

1999.

las imágenes de las revistas han influido en su concepto de

figura corporal ideal; $47 \%$ reconoce querer perder peso

debido a esta influencia. Correlación entre lectura de

revistas y practicar dietas para perder peso y programas de

ejercicios.

\section{BIBLIOGRAFÍA}

- American Psychiatric Association (1994) Diagnostic and Statistical Manual of Mental Disorders. $4^{\mathrm{a}}$ de. Washington..

- Wolraich, ML. Felice, ME. Drotar, D. eds.(1996) The Classification of Child and Adolescent Mental diagnoses in Primary Care; diagnostic and Statistical Manual for Primary Care (DSM-PC); Child and Adolescent Version., IL: American Academy of Pediatrics. Elk Grove Village

- Strober, M. Freeman, R. Morrell, W. (1997) The long term course of severe anorexia nervosa in adolescents: survival analysis of recovery, relapse and outcome predictor over $10-15$ years in a prospective stuty. Int J Eating disorders ; 22:339-360.

- Kreipe, RE. Dukarm, CP. (1999) Trastornos alimentarios de adolescentes y niños mayores. Pediatrics in Review 20(12): 410-421.

- Montero, R.(Enero 2002) Gordos (C) Copyright Diario El Pais, S.L .El Pais.Es.

- Jules, R. Bemporad (consultado enero 2002) The Prehistory of Anorexia Nervosa (New York). http://www-cyberpsycho.org.

- DiNicola, V.F.C. (1990) Anorexia Multiforma: Self Starvation in Historical and Cultural Context,.
Transcultural Psychiatric ; partI:165-196; part II: 245286.

- Lacey, JM. (1982) Anorexia Nervosa and a Bearded Female Saint. Br Med J. 285:1816-1817.

- Bell, RM. (1985) Holy Anorexia. University Press, Chicago.

- Gull, WW. (1997) The address in medicine delivered before the annual meeting of the British Medical Association, at Oxford. Lancet 1868; 2: 171-176. Citado por Goldbloom DS: The Early Canadian History of Anorexia Nervosa. Can J Psychiatry 42, 163-166.

- Gull, WW. (1997) Anorexia nervosa. Lancet 1888; 1: 516-517. Citado por Goldbloom DS: The Early Canadian History of Anorexia Nervosa. Can J Psychiatry 42, 163-166.

- Selvini-Palozzoli, M. (1985) Anorexia Nervosa: A Syndrome Of The Affluent Society. Transcultural Psychiatric Research Review 22, 199-205.

- Miguel, Amando de. ( 2001) La vida cotidiana de los españoles en el siglo XX. Planeta Historia y Sociedad, Barcelona

- Ayuntamiento de Madrid, Escuela de Sanidad y Consumo, Asociación en Defensa de la Atención a la Anorexia Nerviosa y Bulimia (ADANER) y la Sociedad Española de Nutrición Básica Aplicada (SENBA) (2001) I Simposium Nacional sobre Nutrición y 
Trastornos de la Conducta Alimentaria. Madrid.

- Toro, J.(2000). La Epidemiología de los trastornos de la conducta alimentaria. Medicina Clínica 114: 543544.

- American Psychiatric Association (APA), (1994) IV Diagnostic and Statistical Manual of disorders $\left(4^{a}\right.$ de).

- Ruiz, PM. (2000) Trastornos de la conducta alimentaria en una muestra representativa de adolescentes de Zaragoza [Tésis Doctoral]. Universidad de Zaragoza.

- Lucas, AR. Beard, CM. O'Fallon, WM. Kurland, LT. ( 1991) 50-year trends in the incidence of anorexia nervosa in Rochester, Minn.: a population-based study. Am J Psychiatry 148(7):917-22.

- Pagsberg, AK. Wang, AR. (1994) Epidemiology of anorexia nervosa and bulimia nervosa in Bornholm county, Denmark, 1970-1989. Acta Psychiatr Scand 90 (4) 259-65.

- De La Serna, J.L. (1999) Gran Angular: "La Culpa de la Anorexia". Diario El Mundo, 2 de octubre.

- Durkin, S. (consultado enero 2002) Relationship between female's body image and the mass media. Body image researcha summary. http://www.internationalnodietday.com

- Garner, DM. Garfinkel, PE. Olmstead, MP (1983) Anorexia nervosa: recent developments in research. Darby PL, Garfinkel PE, Garner DM, Coscina DV., eds. Alan R Liss. New York.

- Field, AE. Cheung, L. Wolf, A. Herzog, D. Gortmaker, SL. Colditz, GA. (1999) Exposure to the Mass Media and Weight concerns Amog Girls. Pediatrics 103: 1-5.

- PSIQUIATRIA . (1994) "La cultura de la delgadez". Diario El Mundo; 3 de Marzo.

- Editorial (1999) El Boom Mediático Primaveral sobre la anorexia. Jano Profesional 56:9.

- Xavier Bosh, MD. (2000) Please Don'T Pass The Paella: Eating Disorders Upset Spain. JAMA 283 (11):1.

- Gómez, L. (1999) Washington. Un estudio muestra el impacto de la televisión en la anorexia y la bulimia las series anglosajonas hacen estragos entre las adolescentes de las islas Fiyi. Diario El País, 23.Mayo.
- Social Medicine. Focus. (1999) Sharp Rise in Disordered Esting in Fiji Follows Arrival of Western TV.

- Ewan, S. (1988) "Todas Las Imágenes Del Consumismo". Grijalbo, Mexico.

Verdú, V. (2002) Fútbol y realidad. Diario El País viernes 15 marzo.

- New York Times 12 octubre (1986), sección 12, pg 21 .

- Buddensieg, T. Henning, R. (1984) Industriekultur. Peter Behrens and the AEG. 1984, pg:223.

- Gropius, W. (1965) New Architecture and the Bauhaus. Pág 20.

- Bloomer, K. Moore, Ch. (1977) Body, Memory and Architecture. Pg 44.

- Morandé, G. Casas, J.( 1997) Trastornos de la conducta alimentaria en adolescentes. Anorexia nerviosa, bulimia y cuadros afines. Pediatria Integral 2: 3:243260.

- Pérez -Gaspar, M. Gual, P. De Irala-Estévez, J. Martínez González, MA. Lahortiga, F. Cevera, S. (2000) Prevalencia de trastornos de la conducta alimentaria (TCA) en las adolescentes navarras. Medicina Clínica 114: 481-486.

- Verri, AP. Verticale, MS. Vallero, E. Bellone, S. Nespoli, S.(1997) Television and eating disorders. Study of adolescent eating behavios. Minerva Pediatrics 49 : 235-43.

- Pinhas, L. Toner, BB. Alí, A. Garfinkel, PE. Stuckless, N. (1999) The effects of the ideal of female beauty on mood and body satisfaction. Int $\mathrm{J}$ Eat disord 25:233-6

- Field, AE. Cheung, L. Wolf, AM. Herzog, DB. Gortmaker, SL. Colditz, GA.(1999) Exposure to the mass media and weight concerns among girls. Pediatrics 103: E36 